\title{
RECURRENT CHANGES IN COLONY MORPHOLOGY DEPENDENT ON INTRACOLONY SELECTION OF PROTOTROPHS OCCURRING IN RED YEAST *
}

\author{
ADRIAN M. SRB \\ Cornell University, Ithaca, New York
}

\section{INTRODUCTION}

Received 31.vii.57

Gertarn genetic variants that occur in red, adenine-requiring strains of Saccharomyces cerevisice are readily detected on the basis of colour differences. Instances of such genetic instability in these red yeasts have been reported by Lindegren and Lindegren (1947), by Ephrussi, Hottinguer, and Tavlitzki (1949), and by Roman (1956). The phenomenon reported in this paper was first observed by the writer in the course of experiments in which red yeast had been plated upon media containing different concentrations of sugar. The colonies growing upon 0.5 per cent. glucose medium were observed for the most part to be homogeneous in appearance, and true to type for the culture (fig. I). On the 5.0 per cent. glucose medium, a large number of the red colonies were partly or completely masked by white yeast growing from them (fig. 2). The white yeast tended to occur in irregular but approximately spherical masses. In general appearance, these plates suggested pans of partially popped, red-kerneled popcorn. The results of experiments reported here indicate that this phenomenon in red yeast depends upon a particularly strong selective advantage of spontaneous, adenine-independent mutants under particular conditions of culture.

\section{MATERIALS AND METHODS}

The red, adenine-requiring cultures with which these experiments were done were vegetative transfers from haploid strains $\mathrm{I} 73 / \mathrm{I} a, \mathrm{I} 73 / \mathrm{I} b$, and $174 / 1 b$ (Ephrussi, Hottinguer, and Tavlitzki, 1949). The mutant gene in these strains, to which the adenine deficiency and red pigment are referable, has been designated as ad 2 by Roman (1956). The greater part of the work was done with clones C-34 and G-33, derived respectively from single cells isolated out of strains $173 / \mathrm{r} a$ and 173/1 $b$. Strain C-34 was previously described under the label PC-34 (Srb, 1956), but is here redesignated to avoid confusion with "petite colonie" mutants, sometimes abbreviated as PC. Inocula for plating experiments were grown for 20 to 48 hours in standing liquid culture. The liquid yeast extract medium and the solid yeast extract medium used in plates were basically those described by Leupold and Hottinguer (1954), except that glucose was added to the plating media in various concentrations. Bacto Yeast Morphology Agar was used as a chemically defined plating medium, and either was or was not supplemented with adeninesulphate and/or glucose according to the purposes of an experiment. Standard phosphate buffers were used to control $p \mathrm{H}$ of the media for certain experiments. Inocula onto plates were made out of suspensions of cells in Ringer's solution, and were spread with a glass spreader. All incubations were at $24^{\circ}-26^{\circ} \mathrm{C}$. Determinations of $p \mathrm{H}$ were made with a glass-electrode. Estimations of cell numbers were

* Paper No. 345, Department of Plant Breeding, Cornell University. 
made on the basis of hemocytometer counts or on the basis of counts of colonies derived from cells plated through dilution series. The beta-propiolactone used for mutagenic purposes was kindly supplied by the B. F. Goodrich Company.

\section{RESULTS}

(a) Primary observations

The primary observations leading to the experiments described here were as follows. Cells of red, adenine-requiring strain $\mathrm{I} 73 / \mathrm{I} b$ had been spread on yeast extract agar plates supplemented with glucose at two different levels, 0.5 and 5.0 per cent. After six days' incubation the plates were opened. On the medium with $5^{\circ}$ o per cent. sugar, no purely white colonies were observed but many of the red colonies showed more or less massive eruptions of white yeast. These eruptions, which henceforward will be called bursts, were frequently six or more times the height of the red colonies from which they arose or of the height of red colonies not showing bursts. Usually the general outline of well-developed bursts was roughly spherical. Most frequently, bursts arose from near the centre of the red colonies. However, bursts also arose near the peripheries of the red colonies. Large colonies frequently showed more than one burst, with, in general, the largest burst being near the centre of the colony and the others being smaller and peripheral. Except in the case of very small colonies showing bursts, even the peripheral bursts seldom spilled over onto the medium surrounding the colonies bearing them. Much of the growth of the bursts appeared to be vertical in direction. Cultures established from cells isolated from the bursts proved to be adenineindependent when plated upon Yeast Morphology Agar, and gave rise to white colonies.

On the medium containing 0.5 per cent. sugar, no bursts were observed. Approximately $\mathrm{I}$ per cent. of the colonies were small in size and were either non-pigmented or were brown rather than red. On the basis of work reported by Tavlitzki (195I), these exceptional colonies were thought possibly to be adenine-requiring "littles", which form red pigment only when glucose is in excess and the cells have ceased proliferating because of lack of adenine. Cultures established from the exceptional colonies were found in fact still to be adenine-requiring ; spectroscopic analyses, confirmed by Professor B. Ephrussi, showed a sample of these cultures to have the cytochrome deficiency typical of little yeast. Certain of the red colonies showed sectors, in some instances colourless, and in other instances coloured other than red. The sectors were in part of the typical wedge-shaped kind, flaring out towards the edge of the colony, but other sectors appeared as flecks or dots of differently coloured yeast within a red colony. Cultures established from isolates out of 40 of these sectors proved in the vast majority of instances to be adenine-requirers, which were either "little" yeast or were "big" yeast, showing a colour variation from the typical red of the original adenine-requiring 
strain. Two of the culture isolates, deriving in each instance from a pick from a white dot sector, were found to consist of adenineindependent, non-pigmented cells.

\section{(b) Effects of sugar concentration, of $\mathrm{pH}$, and of adenine}

The frequency of bursts in relation to sugar concentration in the medium was studied in several red, adenine-requiring strains of yeast. Results of such an experiment are shown in table I. For

TABLE I

Effect of glucose concentration on occurrence of bursts in adenine-requiring strains of yeast. Basic medium was yeast extract medium. Each value is based on the count from 4 plates

\begin{tabular}{|c|c|c|c|c|c|c|}
\hline & \multicolumn{6}{|c|}{ Per cent. glucose } \\
\hline & Io & 8 & 5 & 3 & I & 0.5 \\
\hline \multicolumn{7}{|l|}{ Strain $173 / 1 b$. } \\
\hline Total colonies & I 8 I & 162 & I 84 & I 98 & I 75 & I 79 \\
\hline Total colonies with bursts & 46 & 83 & 60 & 25 & 0 & o \\
\hline Total bursts : & $6 \mathrm{I}$ & 122 & 73 & 28 & o & $\mathrm{o}$ \\
\hline Per cent. colonies with bursts & 25 & $5^{\mathrm{I}}$ & 33 & I3 & o & o \\
\hline \multicolumn{7}{|l|}{ Strain C-33 } \\
\hline Total colonies & 147 & 229 & I 59 & I63 & I 63 & 217 \\
\hline Total colonies with bursts & 53 & 88 & $6 \mathrm{I}$ & 34 & o & o \\
\hline Total bursts . . & 77 & I I 8 & 75 & 36 & o & o \\
\hline Per cent. colonies with bursts & 36 & $3^{8}$ & 38 & 21 & o & o \\
\hline \multicolumn{7}{|l|}{ Strain $174 / 1 b$} \\
\hline Total colonies & $22 \mathrm{I}$ & 272 & 228 & 256 & 252 & 233 \\
\hline Total colonies with bursts & 79 & 97 & 96 & 106 & o & O \\
\hline Total bursts . & 100 & 128 & 140 & I 50 & o & o \\
\hline Per cent. colonies with bursts & $3^{6}$ & 36 & 42 & 41 & o & o \\
\hline \multicolumn{7}{|l|}{ Strain $\mathrm{C}-34$} \\
\hline Total colonies & $22 \mathrm{I}$ & 225 & I 98 & I 73 & 162 & 220 \\
\hline Total colonies with bursts & 76 & 75 & 92 & 58 & o & o \\
\hline Total bursts : . & I 02 & 93 & I 24 & 69 & o & o \\
\hline Per cent. colonies with bursts & 34 & 33 & 47 & 34 & o & o \\
\hline
\end{tabular}

each strain at each sugar level the values represent the total of counts from 4 plates, inoculated with a suspension of cells diluted so as to give approximately 50 colonies per plate. The medium was yeast extract medium. The data are consistent in that none of the strains shows bursts at $\mathrm{I} \cdot \mathrm{O}$ or 0.5 per cent. glucose, while all the strains show bursts at $3 \cdot 0$ per cent. glucose and above. The data perhaps suggest that the yeast strains differ among themselves, with reference to frequency of bursts at glucose levels of $3 \cdot 0$ per cent. and above. The number of observations, however, is insufficient to permit firm conclusions as to possible differences among these strains.

Since differences in sugar concentration might be supposed perhaps to be reflected in differences in $p \mathrm{H}$ of the media, the $p \mathrm{H}$ of yeast extract media on which colonies were growing was tested. For media 
supplemented with $5^{\circ} \mathrm{o}$ per cent. glucose the $p \mathrm{H}$ was found to be 4.5 ; for media supplemented with 0.5 per cent. glucose, the $p \mathrm{H}$ was found to be $5 \cdot 0$. Therefore, experiments were done in which the frequency of bursts was observed on media containing $5 \cdot 0$ or 0.5 per cent. glucose, unbuffered or buffered to different $p \mathrm{H}$ levels. The results of such an experiment with strain C-34 are shown in table 2. The data clearly show that, among the $p \mathrm{H}$ levels at which observations were made, bursts do not occur at $p \mathrm{H}$ levels above 4.5 , irrespective of sugar concentration. Bursts do occur at $p \mathrm{H}_{4} \cdot 5$, also

TABLE 2

Effect of $\mathrm{pH}$ of medium on the occurrence of bursts. Six plates per treatment. All plates inoculated from the same culture of strain $C_{-34}$, diluted to provide an estimated 15-20 colonies per plate

\begin{tabular}{|c|c|c|c|c|}
\hline \multirow{2}{*}{ Medium } & & \multicolumn{3}{|c|}{ Mean number colonies per plate with } \\
\hline & & o bursts & I burst & more than I burst \\
\hline \multicolumn{5}{|c|}{ Yeast extract ( 5 per cent. glucose) } \\
\hline Unbuffered ( $p \mathrm{H} 4.5)$ & . & $3 \cdot 0$ & $4 \cdot 3$ & $6 \cdot 8$ \\
\hline Buffered, $p \mathrm{H} 6.5$. & . & $14 \cdot 3$ & $0 \cdot 0$ & $0 \cdot 0$ \\
\hline Buffered, $p \mathrm{H} 5 \cdot 3$ & . & $15 \cdot 2$ & $0 \cdot 0$ & $0 \cdot 0$ \\
\hline Buffered, $p \mathrm{H} 4: 5$ & • & $10 \cdot 2$ & $3 \cdot 7$ & $2 \cdot 0$ \\
\hline \multicolumn{5}{|c|}{ Yeast extract $(0.5$ per cent. glucose $)$} \\
\hline Unbuffered $\left(p \mathrm{H}_{5}{ }^{\circ}\right)$ & . & $15 \cdot 9$ & $0 \cdot 0$ & $0 \cdot 0$ \\
\hline Buffered, $p \mathrm{H} 6 \cdot 7$. & . & $15 \cdot 0$ & $0 \cdot 0$ & $0 \cdot 0$ \\
\hline Buffered, $p \mathrm{H}_{5} \cdot 3$ & . & 15.5 & $0 \cdot 0$ & $0 \cdot 0$ \\
\hline Buffered, $p \mathrm{H} 4.5$ & - & $10 \cdot 7$ & $1 \cdot 4$ & $0 \cdot 2$ \\
\hline
\end{tabular}

irrespective of sugar concentration. As between sugar concentration and $p \mathrm{H}$, then, the controlling factor for appearance of bursts is primarily $p \mathrm{H}$.

At appropriate sugar levels, bursts appeared when strain C-34 was grown on Yeast Morphology Agar supplemented with Io mg. per litre of adenine-sulphate. Therefore, the complex mixture of substances found in yeast extract medium is not essential for the occurrence of bursts in this strain of red yeast. The frequency of bursts in relation to adenine concentration was then studied in strains C-33 and C-34. The basic medium for these experiments was Difco Yeast Morphology Agar, buffered to $p \mathrm{H}_{4} \cdot 7$ and supplemented with 5 per cent. glucose. The results of a typical experiment of this kind, summarised in table 3 , show that with increasing concentration of adenine the bursts become less prominent, although not necessarily less frequent, and finally disappear. At a concentration of $\mathrm{io} \mathrm{mg}$. adenine-sulphate per litre, typical bursts appeared. At $20 \mathrm{mg}$. per litre, no well-developed bursts were observed, but approximately Io per cent. of the red colonies showed slightly protuberant white sectors. Isolates made from these sectors yielded cultures of white, 
adenine-independent cells. At 40 and $80 \mathrm{mg}$. per litre, typical bursts did not appear, and neither did protuberant sectors of the kind just described. Instead, certain of the red colonies showed minute sectors appearing as white dots among the red yeast. Again, isolates made from these dot sectors yielded cultures of white, adenine-independent cells. There seems no reason to doubt that the cells found in bursts, in the protuberant sectors, or in the dot sectors are basically the same. At $160 \mathrm{mg}$. per litre of adenine-sulphate, no sectors of any kind could be detected. However, conditions for detecting sectors on the basis

TABLE 3

Effect of adenine concentration on occurrence of bursts. Basal medium Difco Yeast Morphology Agar, supplemented with 5 per cent. glucose. Each value based on counts of 3 plates, with 150 to 200 colonies per plate

\begin{tabular}{|c|c|c|c|c|}
\hline \multirow{2}{*}{$\begin{array}{l}\text { Mg. per litre } \\
\text { adenine-sulphate }\end{array}$} & \multirow{2}{*}{ Strain } & \multicolumn{3}{|c|}{$\begin{array}{l}\text { Percentage of colonies with } \\
\text { slightly protuberant }\end{array}$} \\
\hline & & bursts & sectors & dot sectors \\
\hline 10 & $\begin{array}{l}\mathrm{C}-34 \\
\mathrm{C}-33\end{array}$ & $\begin{array}{l}4 \cdot 6 \\
7 \cdot 0\end{array}$ & $\begin{array}{l}0 \cdot 0 \\
0 \cdot 0\end{array}$ & $\begin{array}{l}0 \cdot 0 \\
0 \cdot 0\end{array}$ \\
\hline 20 & $\begin{array}{l}\text { C- }-34 \\
\text { C-33 }\end{array}$ & $\begin{array}{l}0 \cdot 0 \\
0 \cdot 0\end{array}$ & $\begin{array}{r}8 \cdot 7 \\
11 \cdot 4\end{array}$ & $\begin{array}{l}0 \cdot 0 \\
0 \cdot 0\end{array}$ \\
\hline 40 & $\begin{array}{l}\text { C-34 } \\
\text { C-33 }\end{array}$ & $\begin{array}{l}0 \cdot 0 \\
0 \cdot 0\end{array}$ & $\begin{array}{l}0 \cdot 0 \\
0 \cdot 0\end{array}$ & $\begin{array}{l}7 \cdot 1 \\
5 \cdot 0\end{array}$ \\
\hline 80 & $\begin{array}{l}\mathrm{C}-34 \\
\mathrm{C}-33\end{array}$ & $\begin{array}{l}0 \cdot 0 \\
0 \cdot 0\end{array}$ & $\begin{array}{l}0 \cdot 0 \\
0 \cdot 0\end{array}$ & $\begin{array}{l}0.5 \\
0.4\end{array}$ \\
\hline 160 & $\begin{array}{l}\text { C- }-34 \\
\text { C-33 }\end{array}$ & $\begin{array}{l}0 \cdot 0 \\
0 \cdot 0\end{array}$ & $\begin{array}{l}0 \cdot 0 \\
0 \cdot 0\end{array}$ & $\begin{array}{l}0 \cdot 0 \\
0 \cdot 0\end{array}$ \\
\hline
\end{tabular}

of colour difference were poor. At this highest concentration of adenine, colonies developed pigment very slowly indeed. Eight days after inoculation of the plates the colonies were colourless, and at Io days the colony colour was only light pink. Inspection of the colonies revealed neither bursts nor protuberances suggesting bursts. It should be said that with each increase in adenine concentration, the average size of colonies deriving from cells of strains C-33 and C-34 was larger. Therefore, well-developed bursts occurred only where adenine concentration was limiting for the growth of these strains.

\section{(c) Experiments on mutation and selection}

The occurrence of white, adenine-independent cells (prototrophs) within colonies of red, adenine-dependent yeast appears to be a mutational phenomenon. Since the mutant cells were manifest only under particular cultural conditions, the question arose as to whether conditions favourable to the appearance of bursts acted by influencing the frequency of mutation or by providing selective advantage to 
spontaneously occurring adenine-independent cells. This issue was explored in several ways.

Standard back-mutation techniques were employed to test the possible effects of treatment of cells of strain C-34 with high $v$. low concentration of glucose, with high $v$. low concentration of adenine, and with high $v$. low $p \mathrm{H}$. No significant differences in frequency of appearance of adenine-independent mutants were found to result from these various treatments. However, strain C-34 has particular disadvantages for back-mutation studies (Srb, I956), and less reliance has been placed on these results than on those from the studies next to be described.

If the burst phenomenon depends upon conditions of intracolony selective advantage, rather than depending upon altered mutation frequency, colonies on 0.5 per cent. glucose medium might be expected to include adenine-independent cells even though bursts do not appear. This proposition was tested in the following manner. Cells from strain C-34 were inoculated onto yeast extract plates either containing 0.5 or $5^{\circ}$ o per cent. glucose. As usual, the red colonies on the 0.5 per cent. plates did not develop bursts ; a high frequency of colonies on the $5^{\circ} \mathrm{O}$ per cent. plates showed bursts. Whole colonies from the 0.5 per cent. plates were scraped up separately with a small spatula, and the cells of each colony were suspended in a small volume of Ringer's solution. The cells from each colony were then spread onto a separate plate of Yeast Morphology Agar not supplemented with adenine, where each prototrophic cell might be expected to form a white colony and where adenine-dependent cells would not grow. The results, summarised in table 4 , indicate that certain colonies not showing bursts must in fact have contained adenine-independent cells. From some of the red colonies, the number of derived adenineindependent colonies was very large. It appears, then, that proliferation of adenine-independent cells may occur within adenine-dependent colonies, even though this proliferation is never so extensive as to result in a burst.

Direct tests were employed to see whether colonies of strain C-34 grown on media with supplements of 0.5 or of 5.0 per cent. glucose are differently favourable for the proliferation of adenine-independent cells. Suspensions of cells of strain C-34, calculated to give about 20 colonies per plate, were spread on yeast extract medium containing either $5^{\circ} \mathrm{o}$ or 0.5 per cent. glucose. After 3 days, when colonies had grown to appreciable size, and before spontaneous bursts had appeared on the $5^{\circ}$ o per cent. glucose plates, the centres of colonies on both kinds of plates were inoculated with white, adenine-independent cells. The inoculations were accomplished as direct transfers from bursts, made with a fine platinum needle. In all instances on the $5^{\circ} \mathrm{O}$ per cent. glucose plates, the inocula proliferated immediately, and in such fashion as to resemble spontaneous bursts (fig. 3). Inocula into colonies on the 0.5 per cent. glucose plates did not proliferate greatly. At a 
time when bursts were well developed on the $5^{\circ} \mathrm{o}$ per cent. glucose plates, inoculated colonies on the 0.5 per cent. plates showed only small white sectors at the points of inocula. These sectors were not elevated above the rest of the surface of their colonies.

Similar results were obtained from an experiment that was identically designed except that the inoculum into colonies was with a prototrophic mutant that had been isolated from a burst and then subcultured many times. Similar results were also obtained when colonies were inoculated with cells of strain I $74 /$ I $d$, a standard adenineindependent strain not derived as a mutant out of an adenine-requiring culture. This latter observation indicates that the growth properties

TABLE 4

Presence of prototrophic cells in colonies not showing bursts. Each value indicates the number of white, adenine-independent colonies appearing when all the cells of a colony of strain C-34 were spread on Yeast Morphology Agar unsupplemented with adenine. Colonies of strain C-34 were grown on 0.5 per cent. glucose yeast extract medium, were red coloured, and had not shown bursts

\begin{tabular}{|r|r|r|r|}
\hline Colony A & 0 & Colony K & 47 \\
B & 0 & $\mathrm{~L}$ & $\mathrm{M}$ \\
$\mathrm{C}$ & 63 & $\mathrm{M}$ & $\mathrm{I}$ \\
$\mathrm{D}$ & $\mathrm{I}$ & $\mathrm{N}$ & $\mathrm{O}$ \\
$\mathrm{E}$ & 7 & $\mathrm{O}$ & $\mathrm{T}$ \\
$\mathrm{F}$ & $6 \mathrm{I}$ & $\mathrm{P}$ & $\mathrm{1}$ \\
$\mathrm{G}$ & $\mathrm{Q}$ & $\mathrm{I}$ \\
$\mathrm{H}$ & $\mathrm{O}$ & $\mathrm{R}$ & $c a .400$ \\
$\mathrm{I}$ & 10 & $\mathrm{~S}$ & 3 \\
$\mathrm{~J}$ & $\mathrm{~T}$ & $\mathrm{~T}$ & 76 \\
\hline
\end{tabular}

of prototrophic cells in bursts are not peculiar to revertants occurring in adenine-dependent strains. The results of the entire experimental series are consistent in indicating that colonies grown under the conditions found in unbuffered $5^{\circ} \mathrm{o}$ per cent. glucose plates provide a favourable environment for the rapid proliferation of adenineindependent cells. The conditions in colonies grown in unbuffered 0.5 per cent. glucose plates do not favour the proliferation of adenineindependent cells.

Another kind of experiment was utilised to measure the probability, under appropriate conditions, of an adenine-independent cell expressing itself as a burst in a colony of red yeast. The technique involved the use of giant colonies (Winge and Laustsen, I937) whose original point inocula consisted of many cells. Known numbers of cells of strain C-34 and of adenine-independent cells from a culture derived out of a burst were suspended together in Ringer's solution. Onetenth $\mathrm{ml}$. inocula from this suspension were then placed as single unspread drops either onto $5^{\circ}$ o per cent. glucose or 0.5 per cent. glucose yeast extract medium. For controls, similar inocula were made from suspensions consisting of the same frequency of cells from strain C-34 but not mixed with adenine-independent cells. The giant colonies formed on 0.5 per cent. glucose did not produce bursts, 
whether or not the inoculum contained added prototrophs. The giant colonies formed on $5^{\circ} \mathrm{O}$ per cent. glucose did form bursts. Comparison of the frequency of bursts from colonies initiated with the mixed suspension as against the frequency of bursts from colonies initiated only with $\mathrm{C}_{-}-34$ cells gave an indication of the probability of recovery as bursts of the adenine-independent cells present in the inocula consisting of the mixed suspension.

Table 5 summarises the results of one experiment of this kind. For the giant colonies derived from a mixed suspension, the single drop inocula were calculated each to contain approximately $65 \times 10^{6}$ red, adenine-requiring cells from strain $\mathrm{C}-34$ and roo adenineindependent cells. To check the numbers of adenine-independent cells, drop inocula of the same kind were spread on Yeast Morphology Agar, where the only colonies growing would be those deriving from the prototrophs. The average number of white, adenine-independent colonies appearing on 6 plates of this kind was 83. The control giant colonies were derived from unspread drop inocula simply containing approximately $65 \times 10^{6}$ cells from strain $\mathrm{C}-34$.

Table 5 shows that no bursts appeared in giant colonies grown on the 0.5 per cent. glucose medium. On 5.0 per cent. glucose, the number of bursts was quite variable from colony to colony, both among colonies constructed out of mixed inocula and among colonies where only spontaneous bursts could be expected. However, the number of bursts was always substantially larger for giant colonies derived from mixed inocula. Comparing giant colonies from mixed inocula with control colonies, the average difference in bursts per colony is 72 . Since about 83 adenine-independent cells were put into each of the mixed colonies, the probability of recovery of such a cell as a burst would appear to have been high. In fact, the data may provide an underestimate of this probability of recovery. Bursts occurring in the giant colonies were often very near one another, so that with time neighbouring bursts fused. It seems probable that certain apparently single bursts may have had more than one point of origin from within the colony.

A number of additional experiments with giant colonies gave essentially similar results. This experimental series confirms that at low $p \mathrm{H}$ and with appropriate adenine concentration prototrophic cells occurring within colonies of red, adenine-requiring yeast have an enormous selective advantage. The advantage is so great that almost any prototrophic cell, occurring independently within the colony, has a high probability of expressing itself as a burst.

\section{(d) The genetics of prototrophs isolated from bursts}

Relatively little is known about the genetics of adenine-independent cells that occur in the bursts. The results of studies that have been made are consistent with the supposition that prototrophs occurring 
in the bursts are revertants at the locus of the gene that determines simultaneously red colour and adenine requirement. A prototrophic culture isolated from a burst in a colony of strain C-33 was crossed with strain I $73 / \mathrm{I} a$. Twelve isolated zygotes reproduced as clones that were all white and adenine-independent. Diploid cells were then allowed to sporulate, and the ascospores were isolated from individual asci. All four spores germinated from I $_{2}$ of the ${ }_{5} 5$ asci

TABLE 5

Occurrence of bursts in artificially constructed giant colonies. Basal medium yeast extract. Counts of bursts made after 5 days. Inoculum for each artificially constructed colony was about $65 \times 10^{6}$ cells of strain $C_{-34}$ and 83 prototrophic cells. Inoculum for each control colony was about $65 \times 10^{6}$ cells of strain $C_{-34}$

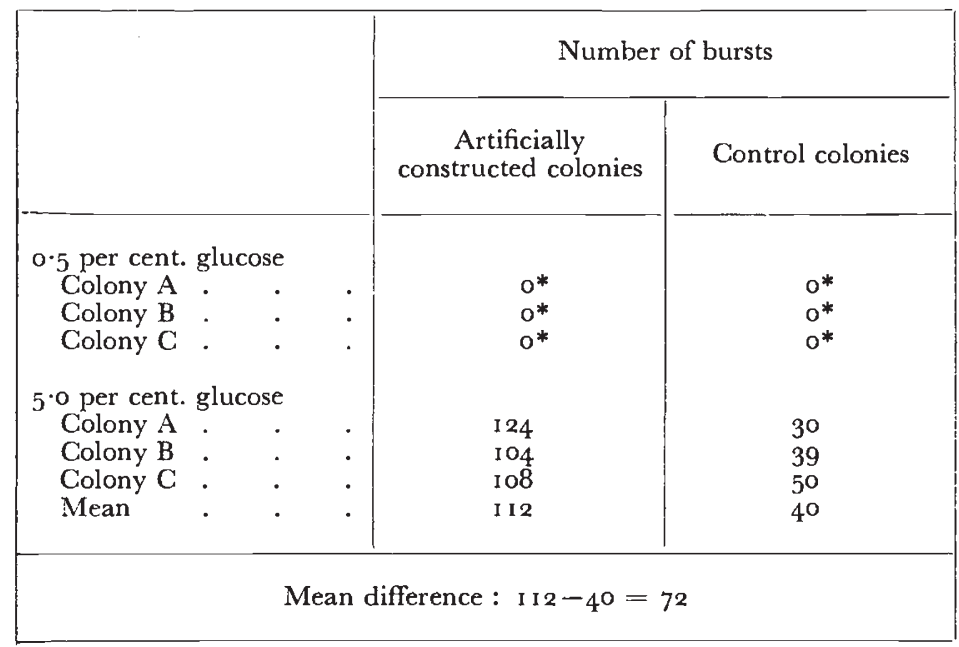

* White dot sectors but no bursts.

dissected. In each instance, the ascus gave a $2: 2$ segregation for the alternatives adenine dependence and adenine independence. A second cross was made with a prototrophic culture isolated from a burst in a colony of strain C-34, the other parent being strain $\mathrm{I} 73 / \mathrm{I} b$, red, adenine-requiring. Ten zygotes provided white, adenineindependent clones. Of the 27 asci that were dissected, 20 gave spores all 4 of which germinated. In I9 of these 20 instances a clear $2: 2$ ratio was observed. In one instance, the germinated spores on first test appeared to give rise to clones 3 of which were prototrophs and I of which was a red adenine-requirer. On retest, it was found that one of the 3 clones of white prototrophs was a mixed culture, containing a small proportion of red, adenine-requiring cells. A reasonable possibility exists that the mixed culture represents an instance of back-mutation occurring fairly early in the history of a clone that was originally adenine-requiring. In any case, no critical evidence exists to show that the prototrophs found in the bursts were something other than back-mutants. The results, in fact, are basically 
similar to those reported (Srb, I956) for a cross involving one of the adenine-requiring strains ( $173 / \mathrm{I} a$ ) and an adenine-independent, canavanine-resistant culture isolated from strain $\mathrm{I} 74 / \mathrm{I} d$. There also the segregation was $2: 2$ for adenine independence-dependence, with the results further indicating the loci for adenine requirement and for canavanine-resistance to be genetically independent. The work of Roman ( I 956), however, shows considerable complexity at the locus for adenine requirement, and the present interpretation that prototrophs isolated from bursts are back-mutants should be taken only as a first approximation.

\section{(e) The occurrence of bursts in other adenine-requiring strains}

Spontaneously occurring "little" mutants of strain C-34 were isolated, and their respiratory deficiency was verified by Professor B. Ephrussi. Then, as described for standard strain C-34, the "little" strain of adenine-requiring yeast was plated on 0.5 and $5^{\circ} \mathrm{O}$ per cent. glucose medium. No bursts were observed in colonies on the 0.5 per cent. glucose medium. Slender, candle-shaped bursts were observed in certain colonies grown on the $5^{\circ}$ o per cent. glucose medium. Cells isolated from these bursts provided prototrophic cultures that formed small, white colonies. The frequency of bursts, considered in terms of the numbers of colonies observed, was considerably smaller than the frequency of bursts in standard strain C-34. The difference in frequencies so calculated may be relatively meaningless, however. Since colony size for " little" strain C-34 is relatively small, the lower frequency of bursts perhaps derives simply from the fact that each colony represents a relatively small population in which spontaneous back-mutation might occur.

Prototrophic cells from bursts of " little" strain C-34 proliferated as bursts when inoculated either into " big " or " little" red colonies of strain $\mathrm{C}-34$ grown on $5^{\circ} \mathrm{o}$ per cent. glucose medium. No proliferation into bursts was observed when such cells were transplanted into colonies grown on 0.5 per cent. glucose medium. Under the conditions of the experiments, the factors affecting intracolony selection of prototrophs seem to operate similarly in "big" and in "little" yeast.

A certain amount of preliminary evidence indicates, however, that genotype may affect the intracolony selection of prototrophs. Cells of strain C-34 were treated for 5 minutes with a $0_{1}$ I per cent. water solution of beta-propiolactone, which acts as a mutagen against yeast (Srb, I 956). The cells were then plated on yeast extract medium. Of the colonies growing from the small percentage of viable cells, many showed sectors recognisable by variations in colour (fig. 4). Isolation of cells from one such sector provided a culture that was adenine-requiring but whose pigmentation was deep red on standard media and very deep purple on media including 8 per cent. yeast 
extract. From other sectors, orange and light pink adenine-requiring strains were isolated. Under appropriate conditions, the purple and the light pink strains produced bursts similar to those produced by strain C-34. The orange strain, however, did not produce bursts, although small white sectors were sometimes observed. Isolations from these sectors gave prototrophic cells. Orange colonies not showing sectors were also proven sometimes to contain prototrophic cells by use of the technique that demonstrated such cells in colonies of strain C-34 grown on 0.5 per cent. glucose. Transplants of prototrophic cells into orange colonies grown on $5^{\circ} \mathrm{o}$ per cent. glucose failed to proliferate into bursts. The genetic relationships between the colour variant strains and strain C-34 were not studied.

\section{DISCUSSION}

The results just described show that bursts of prototrophic cells occur in colonies of red, adenine-requiring yeast under conditions where a partial deficiency of adenine limits growth and where the $p \mathrm{H}$ of the medium is 4.5 . The primary effect of these conditions, with reference to causation of bursts, is the provision of intracolony environments where prototrophic cells proliferate with much greater rapidity than do cells of standard genotype for the colony. This interpretation is forced by the results of experiments where prototrophic cells were actually transferred into colonies of strain C-34 grown on $5^{\circ} \mathrm{O}$ and on 0.5 per cent. glucose media. In the former instance (low $p \mathrm{H})$, typical bursts invariably developed; in the latter instance (higher $p \mathrm{H}$ ), typical bursts never developed. That a limitation on adenine supply contributes to the burst phenomenon was seen in experiments where successively higher adenine concentration in the medium was paralleled by a reduction in size of bursts until they failed entirely to appear.

None of the results rigidly exclude the possibility that $p \mathrm{H}$ and adenine concentration may affect the rate of back-mutation at the locus for adenine requirement. However, altered mutation rate seems not to be required for interpretation of the burst phenomenon. A fair proportion of colonies grown on 0.5 per cent. glucose medium, where bursts did not occur, were shown to include varying numbers of prototrophic cells. Since under favourable conditions even a single prototrophic cell appears to have a high probability of expressing itself as a burst, colonies on 0.5 per cent. glucose may be considered to have had the genetic potential for bursts but not to have expressed this potential.

Two aspects of the selection mechanism involved in the burst phenomenon are of particular interest. One of these is the demonstration that very fine differences in environment may have profound effects on the selection of genotypes. Other conditions being appropriate, a difference of $0.5 p \mathrm{H}$ units, or perhaps less, determines 
whether or not the burst phenomenon may occur. A difference in adenine concentration of only Io mg. per litre may determine whether incipient bursts develop into bursts. The other striking feature of the results has to do with the intensity of intracolony selection. As noted, results with artificially constructed giant colonies indicate the high probability that a singly occurring prototrophic cell will reproduce as a clone that will escape the normal colony confines, under particular environmental circumstances. In this context, the advantages of the giant colony technique for studying a variety of problems in yeast should be emphasised. Skovsted (1956) has utilised this technique to study mutational phenomena affecting morphology in yeast. The present work illustrates that the technique also has possibilities for studies in selection.

The burst phenomenon has many properties in common with a recurrent developmental event, and may be viewed as such. Colonies that develop bursts show characteristic changes in morphology, become bipartite rather than unipartite in gross structure, and have consistently oriented colour differentiation. With correct adjustment of conditions, almost I oo per cent. of colonies in a series of plates could be made to show bursts. Besides appropriate $p \mathrm{H}$ and adenine concentration, these conditions included sufficient time, i.e. up to I4 days' growth period, and a low frequency of colonies per plate, so that each colony achieved reasonably large size. Under such conditions the phenomenon became highly recurrent indeed.

While the suggestion is not being made here that the basis of differentiation in multicellular organisms is spontaneous somatic mutation, the burst phenomenon provides a model showing that certain kinds of recurrent developmental events might feasibly be based on a mechanism involving spontaneous mutation. In addition the model shows that the operation of such a mechanism need not depend, if selection is sufficiently effective, on an unusually high mutation rate. The frequency of back-mutation in the adeninerequiring yeasts has not been possible to define precisely, but our experiments indicate that it may be somewhere between $\mathrm{I} \times \mathrm{IO}^{-6}$ and $\mathrm{I} \times \mathrm{IO}^{-7}$. Since yeast colonies grown under the conditions indicated above may contain upwards of $\mathrm{I} \cdot 7 \times \mathrm{IO}^{8}$ cells, and since a single back-mutant cell is highly likely to express itself as a burst, the high degree of recurrence of the burst phenomenon becomes comprehensible in terms of standard genetic mechanism.

Finally, the burst phenomenon may have some speculative implications for oncology. Beadle (1945), in discussing the somatic mutation theory of the origin of cancer, points out that " the remarkable thing is not that malignancy changes are as frequent as they are but rather that they are not more frequent". Failure of intracolony selection of mutant prototrophs at $p \mathrm{H}^{\circ} \mathrm{O}$ and above, and the consequent absence of bursts, shows that cells which are inordinately proliferative in certain cellular environments may not be so in others. This suggests 


\section{Plate}

Fig. 1.-Strain $174 / 1 b$ on yeast extract medium with 0.5 per cent. glucose. Colonies are 12 days old, and do not show bursts.

FIG. 2.- Strain $174 / 1 b$ on yeast extract medium with $5^{\circ} 0$ per cent. glucose. Colonies are 7 days old, and some show bursts.

Fig. 3.-Colonies of strain C-34 into which prototrophic cells had been introduced after 3 days. Every colony shows a burst. Medium is yeast extract with $5^{\circ} 0$ per cent. glucose.

Fig. 4.- - Sectored colonies of strain C-34. Cells used for inoculum had been treated with beta-propiolactone. 
that mutation frequency might be less important than cellular environment in the development of neoplasms.

\section{SUMMARY}

I. Approximately spherical bursts of white, prototrophic cells frequently arise from colonies of certain strains of red, adeninerequiring yeasts. The occurrence of prototrophs appears to result from back-mutation at the locus for adenine requirement.

2. The bursts occur in colonies grown on media supplemented with $5^{\circ}$ o per cent. glucose but not on media supplemented with $0.5 \mathrm{per}$ cent. glucose. With reference to the burst phenomenon, the primary difference in these media has been shown to be $p \mathrm{H}$ rather than concentration of carbohydrate. Other experiments have shown that well-developed bursts occur only when adenine is partly limiting growth of the red cells.

3. Prototrophic cells are present in colonies grown under conditions where bursts do not arise. Prototrophic cells transferred into colonies of red yeast always proliferate into bursts if the colonies are grown on media that permit the spontaneous occurrence of bursts ; similarly transferred prototrophs never proliferate into bursts if the host colonies are grown on media where spontaneous bursts never occur. The burst phenomenon therefore appears to depend upon environmental conditions such that prototrophs have selective advantages within colonies of adenine-requiring cells.

4. Experiments with artificially constructed giant colonies show that any independently occurring prototrophic cell has a high probability of expressing itself as a burst, when certain environmental conditions are met.

5. Some implications of the burst phenomenon for general problems in development are discussed.

Acknowledgments.-This work was initiated and largely carried out at the Laboratoire de Génétique, de la Faculté des Sciences, Paris, where the author's visit was supported by a Fulbright Award and Guggenheim Fellowship. A large debt of gratitude is due Professor B. Ephrussi, who acted as laboratory host, and provided helpful suggestions as well as materials and space. G. Burtin gave technical assistance. $H$. de Margerie-Hottinguer helped with certain experiments. The work was continued at Cornell, supported by research grant C-1 256 from the National Cancer Institute of the National Institutes of Health, Public Health Service.

\section{REFERENCES}

BeAdle, G. W. I945. Biochemical genetics. Chem. Revs., 37, I5-96.

EPHRUSSI, B., hotTINGUER, H., AND TAVlitzKi, J. I 949 . Action de l'acriflavine sur les levures. II. Étude génétique du mutant "petite colonie". Ann. Inst. Past., 76, 419-450.

LECPOLD, U., AND HOTTINGUER, H. I954. Some data on segregation in Saccharomyces. Heredity, 8, 243-258.

uindegren, G. C., AND lindegren, G. 1947. Depletion mutation in Saccharomvres. P.N.A.S., 33, 314-318. 
ROMAN, H. 1956. A system selective for mutations affecting the synthesis of adenine in yeast. Ctes rend. Lab. Carlsberg, Ser. Physiol., 26, 299-3 I 4.

skovsted, A. 1956. Some unstable mutations in yeast. Ctes rend. Lab. Carlsberg, Ser. Physiol., 26, 335-347.

SRB, A. M. 1956. Spontaneous and chemically-induced mutations giving rise to canavanine resistance in yeast. Ctes rend. Lab. Carlsberg, 'Ser. Physiol., $26,3_{3} 6_{3}-$ 380.

TAVlitzki, J. I95 I. Sur les conditions de la formation de pigment chez une levure rouge. Rev. Can. Biol., 10, 48-59.

WINGE, ø., AND LAUSTSEN, o. 1937. On two types of spore germination, and on genetic segregations in Saccharomyces, demonstrated through single-spore cultures. Ctes rend. Lab. Carlsberg, Ser. Physiol., 22, 99-I 16. 